\title{
La contribución de la Unión Europea a los grandes desafíos de la sociedad internacional
}

\author{
The European Union's contribution to great challenges \\ of the international society \\ Pablo Antonio Fernández Sánchez \\ Catedrático de Derecho Internacional Público y Relaciones Internacionales \\ Universidad de Sevilla \\ pafernandez@us.es
}

doi: http://dx.doi.org/10.18543/ced-57-2017pp17-25

\begin{abstract}
Resumen: Este monográfico recoge siete contribuciones sobre algunos de los temas abordados en el marco de la Red de Excelencia «Nuevos Desafíos del Derecho Internacional», del Plan Nacional de I+D+i, DER2015-69273-REDT y del Proyecto de Excelencia I+D «Las respuestas del Derecho Internacional y Europeo a los nuevos riesgos y amenazas contra la seguridad humana», del Plan Nacional de I+D+i, DER2015-65906-P. Este ejemplar sobre «La Contribución de la Unión Europea a los grandes desafíos de la sociedad internacional» constituye en sí mismo uno de los resultados científicos de estos proyectos en los que participan investigadores de diversas universidades españolas coordinados por el Profesor Pablo Antonio Fernández Sánchez.
\end{abstract}

Abstract: This monographic issue includes seven contributions on some of the topics covered by the Excellence Network «New Challenges of International Law», the National $R \& D \&$ I Plan, DER2015-69273-REDT and the $R \& D$ Excellence Project «The responses of International and European Law to the new risks and threats against human security», of the National $R \& D \&$ I Plan, DER2015-65906-P. This special issue on «The contribution of the European Union to the great challenges of international society» is in itself one of the scientific results of these projects in which researchers from several Spanish universities participate under the supervision of Professor Pablo Antonio Fernández Sánchez.

En el marco de la Red de Excelencia «Nuevos Desafíos del Derecho Internacional», del Plan Nacional de I+D+i, DER2015-69273-REDT y del Proyecto de Excelencia I+D «Las respuestas del Derecho Internacional y Europeo a los nuevos riesgos y amenazas contra la seguridad humana», del Plan Nacional de I+D+i, DER2015-65906-P decidimos ofrecer la posibili- 
dad de realizar un monográfico en esta Revista sobre algunos de los temas que estamos abordando en estos dos proyectos.

De esta forma, se elaboró una llamada a presentación de propuestas y de todas ellas, fueron seleccionadas las que conforman este monográfico, una vez pasados los filtros correspondientes de preselección por parte del IP de los proyectos, de la Directora de la Revista y del Consejo de Redacción.

Todos los artículos pasaron por el sistema preceptivo de la Revista de double blind peer-review, que garantizaba su calidad y su adecuación a los estándares científicos de la Revista.

La selección de los siete artículos que se presentan en este número responde a la temática de investigación generada, tanto en la Red de Excelencia como en el Proyecto de Excelencia, ambas financiadas por el MINECO y los FEDER-UE.

La temática general de la contribución de la UE a los grandes desafíos de la sociedad internacional aconsejaba abordar una variada casuística, con la conciencia de que no se agotaban todas las oportunidades que eran posible, sobre todo, teniendo en cuenta la amplitud de los componentes de la Red que cuenta con más de 60 investigadores de doce universidades españolas y del Proyectos en el que están involucrados investigadores de Europa y América.

Consciente de esta situación, se vio conveniente analizar una de las grandes preocupaciones del Derecho Internacional y de la Unión Europea en el marco de una sociedad internacional tan interdependiente y global como la actual: el arbitraje de inversiones.

El Tratado de Lisboa otorgó competencias exclusivas a la UE en materia de inversiones extranjeras directas. Esta nueva carga competencial no sólo suponía un desafío en el marco de la política exterior de la UE sino que requería nuevos mecanismos que dieran soluciones a las controversias derivadas de la actividad inversora privada en Estados extranjeros.

Cuando en Derecho Internacional se habla de solución de controversias, siempre se tiene en mente el principio de libertad de medios. Sin embargo, cuando hablamos de la intervención de terceros privados, poco habituados a los medios internacionales de solución de controversias, por su imprecisión y sometimiento a los avatares políticos, hay una tendencia a la institucionalización del arbitraje como medio. Su carácter ad hoc, su facilidad de composición, su inmediatez, su formalidad ligera, su intervención directa de las partes en la selección de los árbitros o su preacuerdo de formalidades procesales, etc. le hacen idóneo. También resultan idóneos foros de elección como CIADI, UNCITRAL o el Instituto de Arbitraje de la Cámara de Comercio de Estocolmo.

Ahora bien, también la conformación de Tribunales preconstituidos puede ser una solución, que revestiría a sus decisiones de mayor imparcialidad, si cabe. De esta forma, la Comisión Europea ha propuesto la creación 
de un Tribunal Internacional de Inversiones, incluyendo un Tribunal de Primera Instancia y un Tribunal de Apelaciones. La composición, el sistema de elección de los jueces, las reglas aplicables, la multilateralidad son temas que deben ser analizados con sosiego. Por ello, entre los trabajos que se incluyen en este monográfico se ha aceptado el análisis que ha ofrecido la Prof. a Dra. Ana Mercedes López Rodríguez, Profesora Titular de Derecho Internacional Privado de la Universidad Loyola de Andalucía.

Otra cuestión que ha sido seleccionada es la complementariedad de las normas internacionales de protección y promoción de la diversidad de las expresiones culturales, en el marco de la política cultural de la UE. De nuevo, pues, nos centramos en otra de las grandes contribuciones de la UE a los desafíos del Derecho Internacional.

Desde 2007 está en vigor la Convención de la UNESCO sobre la Protección y promoción de la Diversidad de las Expresiones Culturales que la UE impulsó con la idea de establecer un pilar cultural en la gobernanza internacional.

La UE no dispone de competencias exclusivas en la política cultural, por tanto, comparte con los Estados Miembros el diseño y la ejecución de esta política. De esta forma, el abordaje de esta materia resultaba de interés para el monográfico, a pesar de que su análisis afrontaba tan solo las situaciones ad intra y no ad extra. Ello, lejos de resultar un déficit para el objetivo central del monográfico, se convertiría en un importante revulsivo dado que conociendo el modelo de integración de las normas contempladas por la Convención de la UNESCO podría resultar de enorme utilidad para los emprendedores de los aspectos culturales en el marco de la gobernanza global.

La Prof. Dra. Belén Becerril Atienza, de la Universidad CEU San Pablo ha elaborado una artículo sobre este desafío tan importante.

Entre los temas propuestos se hallaba uno que englobaba dos aspectos de proyección estratégica que era el papel de la mujer en la Agenda de Seguridad y Defensa de la UE y el Programa de Naciones Unidas sobre «la mujer, la paz y la seguridad».

Son dos aspectos aparentemente diversos pero que la Prof. ${ }^{a}$ Dra. Carolina Jiménez Sánchez, de la Universidad de Málaga ha sabido abordar, de tal manera que resultara imprescindible para su incorporación en este monográfico.

En verdad se trata de analizar cómo se ha implementado el Programa de Naciones Unidas sobre «la mujer, la paz y la seguridad» que adoptó el Consejo de Seguridad de Naciones Unidas en el año 2000, consciente de la necesidad de enfocar más adecuadamente el rol de la mujer en los procesos de paz, tanto como actores, como víctimas. Este nuevo enfoque permitiría una concepción global diferente de la seguridad. 
La pretensión del Programa, como señala la propia Prof. a Jiménez Sánchez, era servir de «fuerza transformadora... (que hagan)... evolucionar, ante todo, las «ideas», las concepciones patriarcales sobre la seguridad».

La UE, actor global en materia de seguridad, ha ido estableciendo marcos normativos, orientaciones generales, indicadores de mejoras, acciones proactivas, etc. De hecho, en las operaciones de gestión de crisis internacionales, la UE ha establecido asesores de género, que han ido analizando los casos de abuso y explotación sexual, la violencia contra las mujeres, etc. Igualmente, la UE ha establecido medidas en relación con las mujeres solicitantes de asilo y las buenas prácticas para su protección. Ha incluido a mujeres en los puestos de toma de decisiones, etc.

Obviamente, la política de seguridad y defensa tampoco es una política exclusiva de la UE por lo que se requiere el concurso de los Estados Miembros. Éstos han establecido planes de acción que han ido adoptando a medida que las exigencias de la propia UE eran más precisas.

Es verdad que no todos los Estados Miembros de la UE han adoptado Planes Nacionales. Todo ello es objeto de análisis en este artículo, con tablas de alto interés donde visualizar los Estados Miembros que han adoptado ya sus Planes Nacionales, los que no lo han adoptado, los que habiéndolo adoptado han sido objeto de reforma y actualización, etc.

España adoptó tempranamente el Plan Nacional, en 2007. Sin embargo no ha sido objeto de renovación y mejora. Por ello, el artículo recoge apartados específicos destinados al análisis de la cuestión en España.

Otro tema que suscitó el interés de la Revista, en cuanto a las propuestas recibidas, fue el tema del enfoque que se aportaba desde la UE para el tratamiento de la mutilación femenina. Este tema tenía mucho que ver con uno de los grandes desafíos de la comunidad internacional que es el de la integración de los inmigrantes, en el respeto de su diversidad. Evidentemente este desafío es especialmente interesante en el marco europeo, no sólo porque supone uno de los espacios geográficos más inclusivos del mundo sino porque la dimensión del respeto de los derechos humanos, especialmente en el caso de las niñas y las mujeres permitirán aflorar los problemas jurídicos subyacentes.

La reflexión que ofrecía la Prof. a Dra. Julia Ropero Carrasco, Profesora Titular de Derecho Penal de la Universidad Rey Juan Carlos resultaba idónea para conformar el grupo de artículos que visualizara la contribución de la UE a los grandes desafíos de la sociedad internacional. Los tres elementos: inmigración, integración y diversidad, a través de un caso especifico pero significativo: la mutilación genital en su dimensión del tratamiento que hace la UE.

La Prof. ${ }^{a}$ Ropero Carrasco se pregunta si en el tema de la mutilación genital hay cabida para la integración. Sus respuestas son eminen- 
temente penalistas pero también hace análisis integradores de otros derechos como el propio del Derecho Internacional, en su dimensión europea, como los supuestos del asilo y el refugio y el de la jurisdicción internacional.

Los cuestionamientos culturales, como si se tratara del velo islámico o el ayuno del Ramadán, son desterrados radicalmente porque la mutilación genital afecta a la integridad física y estas cuestiones son orden público europeo. Por tanto, su práctica es rechazada por la sociedad y, por tanto, entra dentro del ámbito penal.

El planteamiento de las contradicciones en materia de asilo y refugio ocupa una parte del análisis en este artículo, lo que me parece un acierto y el enfoque sistémico, en el marco internacional, europeo y nacional, así como sociológico, teniendo en cuenta elementos culturales, humanitarios, antropológicos, políticos, etc.

En un monográfico como éste, diverso pero integrador, no podían faltar los desafíos relacionados con la protección del medio ambiente, especialmente la lucha contra el cambio climático.

En este marco hemos aceptado dos propuestas, una que tiene que ver con las contribuciones de la UE a los desafíos que representa la protección del medio ambiente: la diplomacia europea en materia de lucha contra el cambio climático que aborda el Prof. Dr. Justo Corti Varela, Profesor Adjunto de Derecho Internacional y Europeo de la Universidad CEU San Pablo. El segundo, sobre la contribución de la UE al desarrollo del régimen internacional en materia de cambio climático: el paquete europeo sobre clima y energía en el contexto de la acción internacional, que desarrolla la Prof. ${ }^{a}$ Dra. Rosa Giles Carnero, Profesora Titular de Derecho Internacional Público y Relaciones Internacionales de la Universidad de Huelva. Ambos son experimentados expertos en los temas que desarrollan.

Partiendo de la necesidad de abordar un análisis profundo de los mecanismos utilizados por la diplomacia europea, a raíz de la irrelevancia de su papel en Copenhague (2009), el Prof. Corti Varela propone un análisis sobre la diplomacia interna de la UE y su rol en las distintas negociaciones internacionales en materia de cambio climático. Por tanto, su aspiración, más allá de detectar las razones de los éxitos y fracasos de la diplomacia europea en esta materia de gobernanza global, es comprender las vicisitudes del liderazgo europeo, en relación con las fuerzas centrípetas y centrífugas que han conformado todo el proceso.

Para influir en la agenda medioambiental internacional, la UE debe conocer mucho mejor los intereses particulares de sus propios socios y a sus contrapartes, sobre todo, EEUU y China para aunar esfuerzos y conciliar intereses. 
Los éxitos relativos de París parecen éxitos circunstanciales. El propio autor ya se pregunta por las consecuencias en el desequilibrio de obligaciones que va a suponer la prometida retirada de Trump de los Acuerdos de París.

A los efectos internos también resulta bastante descorazonador la falta de comunitarización de la política energética, indisolublemente unida a la política climática. Los Estados Miembros, aun hoy día, disponen de intereses en materia de carbón, de petróleo, de energía nuclear, de energías renovables, etc. lo que dificulta el consenso interno. Si a ello unimos las reglas de la competencia, la estructuras de los mercados, el coste para los consumidores, etc. se comprenderán mejor las dificultades.

A los efectos externos, la exportabilidad del modelo no ha producido efectos significativos, aunque el modelo del comercio de emisiones, copiado de modelos interestatales de EEUU, si ha tenido efectos, al menos para confiarle a la UE un cierto liderazgo. Sin embargo, los modelos europeos no suponían intereses para los Estados emergentes que querían y quieren, a toda costa, no tocar su modelo productivo para no hacer peligrar su crecimiento económico.

La diplomacia europea se vio desbordada y no fue capaz de ofrecer soluciones imaginativas para la conciliación de todos los intereses en juego. Su nuevo rol de búsqueda de intermediación entre EEUU y China ha producido algunos elementos positivos, sin embargo, la posible retirada de EEUU de la diplomacia climática va a suponer más esfuerzos añadidos a la diplomacia europea.

En cuanto al paquete europeo sobre clima y energía, se analizan dos contextos secuenciales diferentes, aunque no distintos: el segundo periodo de cumplimiento del Protocolo de Kioto y la contribución determinada a nivel nacional en el Acuerdo de París.

El Protocolo de Kioto tuvo el privilegio de asegurar una sustancial disminución de las emisiones de gases de efectos invernadero, principalmente $\mathrm{CO}_{2}$ por la imposición de obligaciones diferenciadas para los Estados más desarrollados. Es verdad que se establecieron dos periodos, uno que abarcaba desde la entrada en vigor del Protocolo de Kioto hasta el 31 de diciembre de 2012 y otro que debería negociarse para que entrara en vigor el 1 de enero de 2013 y que fuera de aplicación hasta 2020.

Es verdad que el Protocolo de Kioto no supuso un instrumento eficaz porque las medidas de mitigación que desarrolló no fueron ya suficientes para la situación del clima. El sistema del principio de responsabilidades comunes pero diferenciadas impidió la inclusión de Estados Unidos y las economías emergentes, como China, India, Brasil, etc quedaron también fuera del sistema.

A finales de 2012 no se consigue establecer un marco obligacional para el segundo periodo del Protocolo de Kioto, lo que supone la salida de algu- 
nos Estados importantes del sistema y la aceptación de una Enmienda, la llamada Enmienda de Doha con la extensión de las obligaciones iniciales de Kioto pero que a día de día, aún no ha entrado en vigor.

Estados Unidos y China apostaron por un nuevo Acuerdo, por lo que se desarrolló un nuevo tratado internacional, ya en vigor, el Acuerdo de París de 12 de diciembre de 2015 (en vigor desde el 4 de noviembre de 2016).

La UE, a pesar de su fracaso diplomático de no encontrar compromisos internacionales al segundo periodo del Protocolo de Kioto, de 2013 a 2020, siguió su lucha climática, de forma unilateral, imponiendo a nivel interno un paquete de normas sobre clima y energía, con medidas para la mitigación de los efectos del cambio climático. Alcanzaría hasta el $30 \%$ de reducción del grado de emisiones hasta 2020, siempre y cuando hubiera estrategias comparables. También modificaría su sistema de mercado de emisiones.

La pretensión de la UE es servir de espejo global para establecer medidas en una economía post carbono, manteniendo la competitividad. De esta forma, pretende ser ejemplo de cómo un marco regional puede servir de interacción con el sistema internacional.

En el marco del Acuerdo de París, la UE se ha comprometido a la reducción del $40 \%$ de las emisiones para 2040 sobre la base de lo que emitía en 1990 y subir las renovables hasta el 27\%. Se mantendrá el sistema del comercio de emisiones y establecería un nuevo paquete de acciones sobre clima y energía.

Hay que tener en cuenta, no obstante, que el Acuerdo de París, a los efectos de la UE, es un tratado mixto, firmado por la UE y por los Estados Miembros y, si bien la UE y muchos Estados Miembros lo han ratificado, hay otros Estados Miembros de la UE que aún no han presentado su consentimiento.

Por último, parecía de gran importancia aceptar la propuesta del Prof. Dr. Rafael Rodríguez Prieto, Profesor Titular de Filosofía del Derecho de la Universidad Pablo de Olavide, de Sevilla. Se trata de una reflexión documentada y un análisis crítico sobre la neutralidad y la imparcialidad del mundo digital, de la red, teniendo en cuenta que este desafío es global porque el mundo cibernético no conoce fronteras y opera desde cualquier lugar del mundo. Por ello, el análisis del Prof. Rodríguez Prieto se debería centrar en la política de la UE sobre internet.

El Supervisor Europeo de Protección de Datos vela por el tratamiento de la información personal y por la intimidad en el mundo cibernético, que son derechos fundamentales. Por otro lado había que considerar otros derechos como el de información, con las dificultades inherentes a los contenidos plurales y sin control que ofrece internet.

La idea de la UE es la regulación de la neutralidad de la Red, protegiendo y garantizando los derechos de los ciudadanos. Sin embargo, las 
vías por las que la UE trata de garantizar la neutralidad no son convincentes. De esta forma, habría que buscar una tercera vía que bien pudiera ser la concepción imparcial de la Red, más que la neutral. Ello se debe al proceso de concentración empresarial que permite la obtención y el intercambio de datos que traspasan, incluso, fronteras nacionales. Empresas como Google o Facebook suponen una concentración inimaginable hasta ahora, de todos los contenidos de la Red.

La regulación jurídica de estas cuestiones en la UE se han centrado en las reglas que salvaguardan el tráfico en la Red que «ha de tratarse de forma equitativa, sin discriminación, restricción o interferencia, independientemente del emisor, el receptor, el tipo, el contenido, el dispositivo, el servicio o la aplicación». Esta loable pretensión cuenta con tres excepciones para la intervención del tráfico de datos: la orden judicial, las garantías de seguridad en Internet y la congestión del tráfico de datos.

Ahora bien, la regulación europea permita que haya diferentes categorías de tráfico de datos cuando se produzca congestión y los operadores tendrían, entonces, la posibilidad de regular las redes de comunicación, con lo peligroso que supone que puedan desarrollarse ideas, amparadas por esta norma, que ofrezcan paquetes diferenciados de información. Esto haría peligrar la neutralidad de la Red.

Las críticas están servidas. Hay quienes consideran que la neutralidad de la Red es una intromisión ilegítima en los derechos del libre mercado y quienes consideran que esta regulación deja demasiadas lagunas, con deficiencias jurídicas importantes destinadas a interpretaciones interesadas, sobre todo de las operadoras de comunicaciones o compañías suministradoras de contenidos, con las consecuencias para una desregulación.

De cualquier manera este tema ha llegado y se va a quedar por mucho tiempo porque hay poca conciencia en cuanto a la forma de regularlo y la UE se debate, desgraciadamente, entre la protección de los derechos de los ciudadanos y los derechos corporativos.

Por último, este número de Cuadernos Europeos de Deusto cierra, como viene siendo habitual, con los comentarios de David Ordóñez Solís a la jurisprudencia reciente del Tribunal de Justicia de la Unión Europea y con una Crónica de la actualidad institucional y económica de España en el marco de la Unión Europea elaborada por Beatriz Iñarritu.

\section{Sobre el autor}

Pablo Antonio Fernández Sánchez es Catedrático de Derecho Internacional Público y Relaciones Internacionales de la Universidad de Sevilla (España) y Titular de la Cátedra Jean Monnet de la Unión Europea. 
Es Investigador Principal de Proyectos Internacionales, Europeos y Nacionales, centrando sus líneas de investigación en el marco del Derecho Europeo, en la protección europea de los derechos humanos, en política exterior europea y en seguridad medioambiental. Entre sus principales libros en temática europea, se pueden señalar: Las Obligaciones de los Estados en el marco del Convenio Europeo de Derechos Humanos, Ministerio de Justicia, Madrid, ISBN 84-505- 5786-0, 1987; Derecho Comunitario de la Inmigración, Atelier, Barcelona, ISBN: 978-84- 96354-68-5, 2006; Integración Europea a través de derechos fundamentales: de un sistema binario a otro integrado (Coord. junto a Javier García Roca), Centro de Estudios Políticos y Constitucionales, Madrid (ISBN: 978-84- .259-1463- 8), 2009; La Obra Jurídica del Consejo de Europa (Ed.), Gandulfo Ediciones, Sevilla (ISBN: 978-84-613-9549-1), 2010; El Diálogo entre los Sistemas Europeo y Americano de Derechos Humanos (Coordinador junto a F. Javier García Roca, Pablo Santolaya Machetti y Raúl Canosa Usera), Civitas, Thomson Reuters, Pamplona, 2012. (ISBN: 978-84-470-3969-2).

\section{About the author}

Pablo Antonio Fernández Sánchez is Professor of Public International Law and International Relations at the University of Seville (Spain) and holder of the Jean Monnet Chair of the European Union.

$\mathrm{He}$ is Principal Investigator of International, European and National Projects, concentrating his lines of research within the framework of European Law, European protection of human rights, European foreign policy and environmental security. Among his main books on European themes are: Las Obligaciones de los Estados en el marco del Convenio Europeo de Derechos Humanos, Ministerio de Justicia, Madrid, ISBN 84-505- 5786-0, 1987; Derecho Comunitario de la Inmigración, Atelier, Barcelona, ISBN: 978-84- 96354-68-5, 2006; Integración Europea a través de derechos fundamentales: de un sistema binario a otro integrado (Coord. junto a Javier García Roca), Centro de Estudios Políticos y Constitucionales, Madrid (ISBN: 978-84- .259-1463- 8), 2009; La Obra Jurídica del Consejo de Europa (Ed.), Gandulfo Ediciones, Sevilla (ISBN: 978-84-613-9549-1), 2010; El Diálogo entre los Sistemas Europeo y Americano de Derechos Humanos (Coordinador junto a F. Javier García Roca, Pablo Santolaya Machetti y Raúl Canosa Usera), Civitas, Thomson Reuters, Pamplona, 2012. (ISBN: 978-84-470-3969-2). 


\section{Derechos de autor}

Los derechos de autor (para la distribución, comunicación pública, reproducción e inclusión en bases de datos de indexación y repositorios institucionales) de esta publicación (Cuadernos Europeos de Deusto, CED) pertenecen a la editorial Universidad de Deusto. El acceso al contenido digital de cualquier número de Cuadernos Europeos de Deusto es gratuito inmediatamente después de su publicación. Los trabajos podrán leerse, descargarse, copiar y difundir en cualquier medio sin fines comerciales y según lo previsto por la ley; sin la previa autorización de la Editorial (Universidad de Deusto) o el autor. Así mismo, los trabajos editados en CED pueden ser publicados con posterioridad en otros medios o revistas, siempre que el autor indique con claridad y en la primera nota a pie de página que el trabajo se publicó por primera vez en $C E D$, con indicación del número, año, páginas y DOI (si procede). Cualquier otro uso de su contenido en cualquier medio o formato, ahora conocido o desarrollado en el futuro, requiere el permiso previo por escrito del titular de los derechos de autor.

\section{Copyright}

Copyright (for distribution, public communication, reproduction and inclusion in indexation databases and institutional repositories) of this publication (Cuadernos Europeos de Deusto, CED) belongs to the publisher University of Deusto. Access to the digital content of any Issue of Cuadernos Europeos de Deusto is free upon its publication. The content can be read, downloaded, copied, and distributed freely in any medium only for non-commercial purposes and in accordance with any applicable copyright legislation, without prior permission from the copyright holder (University of Deusto) or the author. Thus, the content of $C E D$ can be subsequently published in other media or journals, as long as the author clearly indicates in the first footnote that the work was published in $C E D$ for the first time, indicating the Issue number, year, pages, and DOI (if applicable). Any other use of its content in any medium or format, now known or developed in the future, requires prior written permission of the copyright holder. 